OPEN ACCESS

Edited by:

Liana Fattore,

Consiglio Nazionale Delle Ricerche

(CNR), Italy

Reviewed by:

Tetsuo Yamamori,

RIKEN Brain Science Institute (BSI),

Japan

Fabrizio Sanna

Università degli Studi di Cagliari, Italy

${ }^{*}$ Correspondence:

Susanne Nikolaus

susanne.nikolaus@uni-duesseldorf.de

Received: 30 November 2017 Accepted: 20 February 2018

Published: 14 March 2018

Citation

Nikolaus S, Wittsack H-J, Beu M,

Antke C, De Souza Silva MA

Wickrath F, Müller-Lutz A, Huston JP Antoch G, Müller H-W and Hautzel H (2018) GABAergic Control of Nigrostriatal and Mesolimbic Dopamine in the Rat Brain.

Front. Behav. Neurosci. 12:38.

doi: 10.3389/fnbeh.2018.00038

\section{GABAergic Control of Nigrostriatal and Mesolimbic Dopamine in the Rat Brain}

\author{
Susanne Nikolaus ${ }^{1 *}$, Hans-Jörg Wittsack ${ }^{2}$, Markus Beu ${ }^{1}$, Christina Antke ${ }^{1}$, \\ Maria A. De Souza Silva ${ }^{3}$, Frijthof Wickrath ${ }^{2}$, Anja Müller-Lutz ${ }^{2}$, Joseph P. Huston ${ }^{3}$, \\ Gerald Antoch ${ }^{2}$, Hans-Wilhelm Müller ${ }^{1}$ and Hubertus Hautzel ${ }^{1}$ \\ ${ }^{1}$ Clinic of Nuclear Medicine, University Hospital Düsseldorf, Düsseldorf, Germany, ${ }^{2}$ Department of Diagnostic and \\ Interventional Radiology, Medical Faculty, University Düsseldorf, Düsseldorf, Germany, ${ }^{3}$ Center for Behavioural Neuroscience, \\ Institute of Experimental Psychology, Heinrich-Heine University, Düsseldorf, Germany
}

Purpose: The present study assessed the effects of the $\mathrm{GABA}_{A}$ receptor $(\mathrm{R})$ agonist muscimol (MUS), and the $\mathrm{GABA}_{A} R$ antagonist bicuculline $(\mathrm{BIC})$ on neocortical and subcortical radioligand binding to dopamine $\mathrm{D}_{2 / 3} \mathrm{Rs}$ in relation to motor and exploratory behaviors in the rat.

Methods: $D_{2 / 3} R$ binding was measured with small animal SPECT in baseline and after challenge with either $1 \mathrm{mg} / \mathrm{kg}$ MUS or $1 \mathrm{mg} / \mathrm{kg} \mathrm{BIC}$, using [ $\left.{ }^{123} /\right] \mathrm{IBZM}$ as radioligand. Motor/exploratory behaviors were assessed for $30 \mathrm{~min}$ in an open field prior to radioligand administration. Anatomical information was gained with a dedicated small animal MRI tomograph. Based on the Paxinos rat brain atlas, regions of interest were defined on SPECT-MRI overlays. Estimations of the binding potentials in baseline and after challenges were obtained by computing ratios of the specifically bound compartments to the cerebellar reference region.

Results: After MUS, $D_{2 / 3} R$ binding was significantly reduced in caudateputamen, nucleus accumbens, thalamus, substania nigra/ventral tegmental area, and posterior hippocampus relative to baseline $(0.005 \leq p \leq 0.012)$. In all these areas, except for the thalamus, $D_{2 / 3} R$ binding was negatively correlated with grooming in the first half and positively correlated with various motor/exploratory behaviors in the second half of the testing session. After $\mathrm{BIC}, \mathrm{D}_{2 / 3} \mathrm{R}$ binding was significantly elevated in caudateputamen $(p=0.022)$ and thalamus $(p=0.047)$ relative to baseline. $D_{2 / 3} R$ binding in caudateputamen and thalamus was correlated negatively with sitting duration and sitting frequency and positively with motor/exploratory behaviors in the first half of the testing time.

Conclusions: Findings indicate direct GABAergic control over nigrostriatal and mesolimbic dopamine levels in relation to behavioral action. This may be of relevance for neuropsychiatric conditions such as anxiety disorder and schizophrenia, which are characterized by both dopaminergic and GABAergic dysfunction.

Keywords: $D_{2 / 3}$ receptor, $\left[{ }^{123} \mid\right] I B Z M$, GABA $A$ receptor, muscimol, bicuculline 


\section{INTRODUCTION}

In the nigrostriatal system, the neostriatum or caudateputamen (CP) receives glutamatergic (GLUergic) afferents from neocortex [motor cortex (MC), somatosensory cortex, frontal cortex (FC), prefronal cortex (PFC)] and thalamus (THAL; Johnson et al., 1968; Jones et al., 1977; Künzle, 1977; Jayaraman, 1985) as well as dopaminergic (DAergic) afferents from the pars compacta of the substantia nigra (SNc; Gerfen et al., 1987). In turn, it sends DAergic efferents to THAL, neocortex, and back to the SN (Gerfen, 1984; Tomasi and Volkow, 2013). In the mesolimbic system, the ventral striatum or nucleus accumbens (NAC), receives GLUergic imput from cortical regions, hippocampus (HIPP), amygdala, and cingulate (CING) as well as DAergic input from ventral tegmental area (VTA) and the parafascilular nucleus of the THAL (Powell and Leman, 1976; Baleydier and Mauguiere, 1980; Hara et al., 1989; Sesack et al., 1989; Ishikawa and Nakamura, 2006), with DAergic neurons projecting back to limbic regions including the HIPP (Nazari-Serenjeh et al., 2011).

The DAergic system is under inhibitory $\gamma$-amino butyric acidergic (GABAergic) control (Precht and Yoshida, 1971). From the $\mathrm{CP}, \mathrm{GABAergic}$ projections run either directly or via the external part of the globus pallidus (GPe) and the subthalamic nucleus (STN) to the internal part of the globus pallidus (GPi) and to the pars reticulata of the $\mathrm{SN}(\mathrm{SNr})$. From GPi and $\mathrm{SNr}$, further GABAergic efferents project to THAL (ventral anterior, ventrolateral, dorsomedial, and centromedian nucleus), pedunculopontine nucleus, inferior and superior colliculus, and periaqueducatal gray (Kuo and Carpenter, 1973; Graybiel and Ragsdale, 1979; Herkenham, 1979; Coimbra and Brandao, 1993). In addition, the $\mathrm{CP}$ is inhibited by GABAergic mircrocircuits, which are formed by fast-spiking interneurons and collaterals of descending projection neurons (Groves, 1983). The NAC receives GABAergic input from the PFC (Lee et al., 2014), and, in turn, sends GABAergic efferents back to the VTA as well as to the ventral GP and from the GP to the dorsomedial thalamic nucleus (Ueki et al., 1977; Yamamoto et al., 1983). DA neurons serve to modulate the GABAergic system: in the direct pathway, DA exerts an inhibitory effect on those GABAergic neurons, which project to the GPe, leading to a net disinhibition of the THAL, whereas in the indirect pathway, DA stimulates GABAergic projections to GPi and $\mathrm{SNr}$ with a net inhibitory effect on the THAL. The THAL, in turn, sends GLUergic efferents to MC, FC, PFC, and CING.

The dysfunction of the $\mathrm{GABA}_{\mathrm{A}} \mathrm{R}$ subtype is associated with numerous psychiatric conditions including schizophrenia, anxiety disorders and autism spectrum disorders (Cellot and Cherubini, 2014; Nikolaus et al., 2014b). Intracerebral effects of the $\mathrm{GABA}_{\mathrm{A}} \mathrm{R}$ agonist muscimol (MUS; 5-aminomethylisoxazol-3-ol) and the $\mathrm{GABA}_{\mathrm{A}} \mathrm{R}$ antagonist bicuculline (BIC; (6R)-6-[(5S)-6-methyl-5,6,7,8-tetrahydro[1,3] dioxolo[4,5-

g]isoquinolin-5-yl]furo[3,4-e][1,3]benzodioxol-8(6H)-one) on extracellular DA are region-specific: MUS infusions into the PFC (0.1 and $1 \mathrm{mM}$, Matsumoto et al., 2003) and into the VTA (10-40 $\mu \mathrm{M}$, Westerink et al., 1996, 1998) reduced DA concentrations in CP (Westerink et al., 1996; Matsumoto et al., 2003) and PFC (Westerink et al., 1998). In contrast, MUS infusion into SN (10 $\mu$ M, Santiago and Westerink, 1992) and GP $(100 \mu \mathrm{M}$, Cobb and Abercrombie, 2002, 2003) increased DA levels in $\mathrm{CP}$ and $\mathrm{SN}$, respectively. Furthermore, application into NAC (250 $\mu \mathrm{M}$, Yoshida et al., 1997; $0.5 \mathrm{nM}$, Aono et al., 2008) and VTA (10 and $100 \mu \mathrm{M}$, Klitenick et al., 1992) elevated DA in these regions. However, no effect was observed on prefrontal DA after prefrontal infusion of 50 and $500 \mu \mathrm{M}$ MUS (Santiago et al., 1993).

BIC infusions into SN $(50 \mu \mathrm{M}$, Santiago and Westerink, 1992; Westerink et al., 1992), VTA (200 $\mu \mathrm{M}$, Ikemoto et al., 1997), and PFC (50 and $100 \mu \mathrm{M}$, Karreman and Moghaddam, 1996; 30 and $100 \mu \mathrm{M}$, Matsumoto et al., 2003) elevated DA concentrations in SN and CP (Santiago and Westerink, 1992; Westerink et al., 1992) as well as NAC (Ikemoto et al., 1997) and PFC (Karreman and Moghaddam, 1996; Matsumoto et al., 2003). Similarly, applications into CP $(100 \mu \mathrm{M}$, Smolders et al., 1995) and NAC $(25,50$, or $100 \mu \mathrm{M}$, Yan, 1999; 50 pmol, Aono et al., 2008) increased DA levels in these regions.

We have previously shown that MUS but not BIC reduced radioligand binding to the neostriatal $\mathrm{D}_{2}$ R-like subtype relative to baseline (BAS) and to vehicle. Moreover, motor/exploratory behaviors were diminished after MUS, but elevated after BIC relative to vehicle (Nikolaus et al., 2017). These effects of MUS and $\mathrm{BIC}$ prompted us to assess binding to the $\mathrm{D}_{2} \mathrm{R}$-like subtype separately in $\mathrm{CP}$ and NAC as well as in other cortical and subcortical regions including THAL, SN/VTA, FC, MC, parietal cortex (PC), anterodorsal hippocampus (aHIPP), and posterior hippocampus (pHIPP). In the previous study, for each rat, small volumes of interest (VOIs) had been defined around the neostriatal hot spots of maximum radioactivity accumulations (Nikolaus et al., 2017). This mode of analysis has proven sufficient for a comparatively large region with a high density of $\mathrm{D}_{2} \mathrm{R}$ like binding sites such as the striatum. However, it may be not valid to determine radioligand binding in smaller regions such as SN/VTA, or in cortical or limbic regions with lower amounts of $\mathrm{D}_{2} \mathrm{R}$-like binding sites. Therefore, in the present investigation, images of $\mathrm{D}_{2} \mathrm{R}$-like binding were coregistered with morphological images obtained with a dedicated small animal MRI tomograph, which allowed the transference of the predefined cortical and subcortical VOIs of the Paxinos standard rat brain MRI (Schiffer et al., 2006) to the functional SPECT images and, thus, permitted the first-time in vivo imaging analysis of radioligand binding to $\mathrm{D}_{2} \mathrm{R}$-like binding sites in relevant regions of the rat nigrostriatal and mesolimbic system such as NAC, THAL, SN/VTA, FC, MC, PC, aHIPP, and pHIPP. Additionally, the relation between $\mathrm{D}_{2} \mathrm{R}$-like binding in these regions and motor/exploratory behaviors was assessed with both correlation analysis and cluster analysis.

\section{MATERIALS AND METHODS}

\section{Animals}

Imaging studies of $\mathrm{D}_{2} \mathrm{R}$-like binding sites were conducted on 32 adult male Wistar rats (ZETT, Heinrich-Heine University, Düsseldorf, Germany), weighing $429 \pm 42 \mathrm{~g}$ [mean \pm standard deviation (SD)]. Thereby, animals underwent one SPECT measurement in BAS and one SPECT measurement plus 
behavioral testing after challenge with MUS or BIC $(n=16$, respectively). Morphological images were obtained on eight further male Wistar rats (ZETT, Heinrich-Heine University, Düsseldorf, Germany; weight: $434 \pm 37 \mathrm{~g}$ ). Findings on striatal $\mathrm{D}_{2} \mathrm{R}$-like binding and behavioral data were previously published, with binding data, however, having been obtained with a different mode of analysis (see above; Nikolaus et al., 2017). Rats were maintained in standard macrolon cages $(590 \times$ $380 \times 200 \mathrm{~mm}$; three animals per cage) in a climate cabinet (Scantainer, Scanbur BK, Karslunde, Denmark; temperature: $20^{\circ} \mathrm{C}$; air humidity; $70 \%$ ) with an artificial ligh-dark cycle (lights on at 6:00 a.m., lights off at 6:00 p.m.) and food and water freely available. The study was carried out in accordance with the recommendations of the "Principles of laboratory animal care" (NIH publication No. 86-23, revised 1985) and the German Law on the Protection of Animals. The protocol was approved by the regional authority (Landesamt für Natur, Umwelt und Verbraucherschutz, Nordland-Westfalen, Recklinghausen, Germany).

\section{SPECT Studies}

SPECT measurements of $\mathrm{D}_{2}$ R-like binding sites were performed with the TierSPECT (Schramm et al., 2000) as previously described (Nikolaus et al., 2017). Briefly, each rat underwent imaging studies in BAS and after intraperitoneal (i.p.) injection of MUS (Sigma-Aldrich, Taufkirchen, Germany; dose: $1 \mathrm{mg} / \mathrm{kg}$, concentration: $1 \mathrm{mg} / \mathrm{ml}$ ) or BIC (Sigma-Aldrich, Taufkirchen, Germany; dose: $1 \mathrm{mg} / \mathrm{kg}$, concentration: $1 \mathrm{mg} / \mathrm{ml}$ ).

Subsequently, animals were anesthetized with ketaminehydrochloride (Ketavet ${ }^{\circledR}$, Pharmacia GmbH, Erlangen, Germany; dose: $0.9 \mathrm{ml} / \mathrm{kg}$ i.p., concentration: $100 \mathrm{mg} / \mathrm{ml}$ ) and xylazinehydrochloride (Rompun ${ }^{\circledR}$ Bayer, Leverkusen, Germany; dose: $0.4 \mathrm{ml} / \mathrm{kg}$ i.p., concentration: $0.02 \mathrm{mg} / \mathrm{ml})$. The employed radioligand $\left[{ }^{123} \mathrm{I}\right] \mathrm{S}$-3-iodo-N-(1-ethyl-2-pyrrolidinyl) methyl-2-hydroxy-6-methoxy benzamide ([ $\left.\left.{ }^{123} \mathrm{I}\right] \mathrm{IBZM}\right)$ has a high affinity for binding sites of the $\mathrm{D}_{2} \mathrm{R}$-like subtype $\left[\mathrm{D}_{2} \mathrm{R}\right.$ : inhibition constant $\left(K_{i}\right)=1.6 \mathrm{nM}, \mathrm{D}_{3} \mathrm{R}: K_{i}=2.2 \mathrm{nM}$; (Videbaek et al., 2000)]. [ $\left.{ }^{123} \mathrm{I}\right]$ IBZM (GE Healthcare, München, Germany; activity: $25.4 \pm 3.6 \mathrm{MBq}$, concentration: $3.4 \times 10^{-9} \mathrm{~g} / \mathrm{ml}$, specific activity: $>74 \mathrm{TBq} / \mathrm{mmol}$ at reference time) was injected into the lateral tail vein. SPECT measurements were started $75 \mathrm{~min}$ after pharmacological challenge and $45 \mathrm{~min}$ after radioligand administration. Data were acquired over $60 \mathrm{~min}$; thus, animals were kept under anesthesia for a total of $105 \mathrm{~min}$. As to the selection of doses and time intervals between application of challenges, radioligand injection, and initiation of behavioral and SPECT measurements the reader is referred to a previous publication (Nikolaus et al., 2017).

\section{MRI Studies}

Upon anesthization with ketaminehydrochloride (dose: 0.45 $\mathrm{ml} / \mathrm{kg}$ i.p., concentration: $100 \mathrm{mg} / \mathrm{ml}$ ) and xylazinehydrochloride (dose: $0.2 \mathrm{ml} / \mathrm{kg}$ i.p., concentration: $0.02 \mathrm{mg} / \mathrm{ml}$ ), rat heads were scanned with a dedicated small animal MRI tomograph (MRS3000 Pre-clinical MRI, 3.0 T, MR Solutions, Guildford, $\mathrm{UK})$. A rat body volume coil with an inner diameter of $54 \mathrm{~mm}$ was used to transmit the radio frequency pulses and to receive the MR signals. A standard gradient echo pilot scan in three orthogonal directions was used for the positioning of a 3D fast low angle shot (FLASH) MR sequence to acquire high-resolution anatomical images (Haase et al., 1986). The measurement parameters for the 3D FLASH sequence were as follows: image matrix: $192 \times 192$ $\times 96$, interpolated by zero-filling before reconstrution to a 256 $\times 256 \times 128$ matrix in coronal slice orientation; field of view: $64 \times 64 \times 44 \mathrm{~mm}$; spatial resolution: $0.25 \times 0.25 \times 0.69 \mathrm{~mm}$; repetition time: $30 \mathrm{~ms}$; echo time: $4.87 \mathrm{~ms}$; excitation flip angle: $30^{\circ}$; total acquisition time: $553 \mathrm{~s}$.

\section{Behavioral Studies}

Rats underwent behavioral measurements in an open field (Phenotyper ${ }^{\circledR}$, Noldus Information Technology, Wageningen, The Netherlands; dimensions: $45 \times 45 \times 56 \mathrm{~cm}$ ) as previously described (Nikolaus et al., 2013, 2014a, 2016, 2017). Briefly, traveled distance $(\mathrm{cm})$ as well as durations (s) and frequencies $(n)$ of motor and exploratory behaviors (ambulation, sitting, rearing, head-shoulder motility, grooming) were registered in blocks of 5 min for a total of 30 min using EthoVision XT (Noldus Information Technology, Wageningen, The Netherlands).

\section{Evaluation of SPECT Imaging Studies}

$\mathrm{D}_{2 / 3} \mathrm{R}$ imaging data were evaluated with PMOD (version 3.5, PMOD Technologies Ltd., Zürich, Switzerland). Firstly, the SPECT image of each rat was coregistered with a MR image of an animal of the same weight. Then, the respective MR image was coregistered with the Paxinos standard rat brain MRI (Schiffer et al., 2006) provided by PMOD. The necessary mathematical transformations were saved. The SPECT image as coregistered with the fitting MRI was imported using these transformations, which allowed creation of an overlay with the Paxinos standard rat brain MRI. On these overlays, the following volumes of interest (VOIs) were defined: CP, NAC, THAL, SN/VTA, FC, MC, PC, aHIPP, and pHIPP. The tomographic resolution of the employed SPECT camera amounts to 2.8 and $3.4 \mathrm{~mm}$ for ${ }^{99 \mathrm{~m}} \mathrm{Tc}$ and ${ }^{123} \mathrm{I}$, respectively (Schramm et al., 2000). According to the rat brain atlas, all these regions have maximum craniocaudal (CC) and one-sided mediolateral (ML) and dorsoventral (DV; vertical or oblique) dimensions in the range of or beyond the spatial resolution of the imaging system: $\mathrm{CP}, \mathrm{CC}:>4.5 \mathrm{~mm}, \mathrm{ML}: \sim 3.4 \mathrm{~mm}, \mathrm{DV}: \sim 5 \mathrm{~mm}$; NAC, CC: $>3 \mathrm{~mm}, \mathrm{ML}: \sim 2.5 \mathrm{~mm}, \mathrm{DV}: \sim 3 \mathrm{~mm}$; THAL, CC: $>6.0 \mathrm{~mm}$, ML: $\sim 4.5 \mathrm{~mm}, \mathrm{DV}: \sim 3.5 \mathrm{~mm}$; SN/VTA, CC: $>2.5 \mathrm{~mm}$, ML: $\sim 2.8 \mathrm{~mm}, \mathrm{DV}: \sim 3.2 \mathrm{~mm}$; FC, CC: $>3.4 \mathrm{~mm}, \mathrm{ML}: \sim 3.1 \mathrm{~mm}, \mathrm{DV}$ : $\sim 3.8 \mathrm{~mm}$; MC, CC: $>8.4 \mathrm{~mm}$, ML: $\sim 4.0 \mathrm{~mm}, \mathrm{DV}: \sim 4.2 \mathrm{~mm}$; PC, CC: $>7.8 \mathrm{~mm}, \mathrm{ML}: \sim 3.0 \mathrm{~mm}$, DV: $\sim 8.0 \mathrm{~mm}$; HIPP, CC: $>8 \mathrm{~mm}, \mathrm{ML}: \sim 5.0 \mathrm{~mm}, \mathrm{DV}: \sim 6.5 \mathrm{~mm}$ (Paxinos and Watson, 2014). Moreover, in autoradiographic studies performed with a variety of radioligands including $\left[{ }^{123} \mathrm{I}\right] \mathrm{IBZM}$, these regions have been shown to express $\mathrm{D}_{2} \mathrm{R}$-like binding sites (Bouthenet et al., 1987; Verhoeff et al., 1991). Since [ ${ }^{123}$ I]IBZM accumulation in the cerebellum (CER) is non-specific, the CER was used as reference region (REF; see Supplementary Figure). Estimations of regional binding potentials (BPs) for BAS and challenges were obtained according to the simplified reference tissue model by computing ratios of radioactvity counts obtained in the specifically-bound 
compartments (CP, NAC, THAL, SN/VTA, FC, MC, PC, aHIPP, and $\mathrm{pHIPP}$ ) to radioactivity counts in the CER (Ichise et al., 2001).

\section{Statistical Analysis}

Distributions of both regional BPs and behavioral data were tested for normality with the non-parametric KolmogorovSmirnov test $(\alpha=0.05)$. Neither in BAS, nor after MUS or BIC, regional BPs were uniformly normally distributed $(0.021 \leq p \leq$ 0.20 ). This also held for behavioral parameters after both MUS and $\operatorname{BIC}(0.0001 \leq p \leq 0.20)$.

Medians with 25-/75-percentiles were computed for regional BPs. Regional BPs were compared between pre-treatment

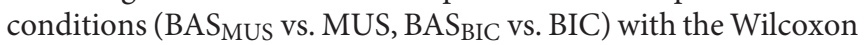
signed rank test for paired samples (two-tailed, $\alpha=0.05$ ). Moreover, percentual differences of BPs relative to BAS were computed for both MUS and BIC. No corrections of the alpha value were made for multiple comparisons. Calculations were performed with IBM SPSS Statistics 23 (IBM SPSS Software Germany, Ehningen, Germany).

In order to gauge the extent of association between regional radioligand binding and motor/exploratory parameters, Spearman rank correlation coefficients $(r ; \alpha=0.05)$ were computed for the individual BPs and behavioral data in the individual time frames $(1-5,6-10,11-15,16-20,21-25$, and $26-$ $30 \mathrm{~min}$ ). Calculations were performed with SigmaStat (version 3.5, Systat Software Inc., Erkrath, Germany).

In addition, cluster analyses were performed for regional BPs and behavioral data (traveled distance and durations and frequencies of ambulation, sitting, rearing, head-shoulder motility, and grooming) in the individual time frames (1-5, 6-10, 11-15, 16-20, 21-25, and 26-30 min) after MUS and after BIC. The individual data were standardized using the Ztransformation [(individual value - variable mean)/SD from the variable mean]. The number of clusters and the centroid mean of each variable in them were determined with an Xmeans algorithm (Pelleg and Moore, 2000). Cluster analyses were calculated with Rapid Miner (version 5.3., Rapid-I GmbH, Dortmund, Germany). The individual values of the behavioral parameters, which entered correlation analysis and cluster analysis, are given for each animal in the Supplementary Table.

\section{RESULTS}

\section{$D_{2 / 3} R$ Binding}

In Figure 1, characteristic coronal images of regional $\left[{ }^{123} \mathrm{I}\right] \mathrm{IBZM}$ accumulations in the BAS condition and after challenge with MUS and BIC, respectively, are presented at different positions from Bregma (Paxinos and Watson, 2014). SPECT images in the conditions BAS $\mathrm{SUS}_{\text {MUS }}$ and MUS were obtained in the same rat. This also holds for $\mathrm{BAS}_{\mathrm{BIC}}$ and BIC.

After MUS (Figure 2), BPs were significantly reduced in CP $(-17 \%, p=0.005)$, NAC $(-20 \%, p=0.012)$, pHIPP $(-19 \%, p$ $=0.022)$, SN/VTA $(-22 \%, p=0.008)$, and THAL $(-20 \%, p=$ $0.028)$ relative to $\mathrm{BAS}_{\mathrm{MUS}}$. There were no differences between BAS $_{\text {MUS }}$ and MUS in FC, MC, PC, aHIPP, and CER $(0.108 \leq p$ $\leq 0.433)$.
After BIC (Figure 3), the thalamic BP was significantly elevated $(+17 \%, p=0.047)$ compared to BAS BIC. Likewise, the post-challenge $\mathrm{BP}$ in the $\mathrm{CP}$ was significantly increased relative to the $\mathrm{BP}$ in $\mathrm{BAS}(+8 \%, p=0.022$; Figure 3$)$. There were no differences between BAS $\mathrm{BIC}_{\mathrm{C}}$ and BIC in NAC, SN/VTA, FC, MC, PC, aHIPP, pHIPP, and CER $(0.130 \leq p \leq 0.678)$.

\section{Correlations Between Regional $D_{2 / 3} R$ Binding and Behaviors}

Table 1 shows the significant $(0.0001 \leq p \leq 0.05)$ positive and negative correlations between regional BPs and behavioral parameters in the individual time frames after treatment with MUS or BIC.

After MUS, lower $\mathrm{D}_{2 / 3} \mathrm{R}$ binding in CP, NAC, SN/VTA, FC, MC, aHIPP, and pHIPP was associated with a reduction of motor/exploratory parameters in the second half of the testing session and an increase of sitting and grooming primarily between 11 and $15 \mathrm{~min}$.

For BIC, the correlation analysis showed an association between lower $\mathrm{D}_{2 / 3} \mathrm{R}$ binding in $\mathrm{CP}, \mathrm{NAC}$, THAL, MC, and aHIPP and more sitting and head-shoulder motility as well as less traveled distance and rearing primarily during the first $5 \mathrm{~min}$ of the testing session.

\section{Cluster Analysis MUS}

The cluster analysis (Table 2) of regional $\mathrm{D}_{2 / 3} \mathrm{R}$ binding data and behavioral variables in the individual time frames yielded two clusters (cluster 1: $n=7$, cluster 2: $n=9$ ). Relative to the second cluster, the first one was characterized by lower centroid means of $\mathrm{D}_{2 / 3} \mathrm{R}$ binding in $\mathrm{CP}, \mathrm{NAC}$, THAL, and FC and higher centroid means of $\mathrm{D}_{2 / 3} \mathrm{R}$ binding in SN/VTA, MC, PC, aHIPP, and pHIPP. Moreover, relative to the second cluster, centroid means in the first one were lower for (1) sitting duration and frequency in the fifth time frame, (2) traveled distance, ambulation duration, ambulation frequency, and frequency of head-shoulder motility in the first, second, third, fourth, and sixth time frame, and (3) rearing duration, rearing frequency, and duration of head-shoulder motility in all time frames. In contrast, centroid means in the first cluster were higher for (1) traveled distance, ambulation duration, ambulation frequency, and frequency of head-shoulder motility in the fifth time frame, (2) sitting duration and sitting freuency in the first, second, third, fourth, and sixth time frame, and (3) both grooming duration and grooming frequency in all time frames.

\section{BIC}

For treatment with BIC, the cluster analysis (Table 2) of regional $\mathrm{D}_{2 / 3} \mathrm{R}$ binding data and behavioral variables in the individual time frames also yielded two clusters (cluster $1: n=6$, cluster 2: $n=10$ ). Relative to the second cluster, the first one was characterized by lower centroid means of $\mathrm{D}_{2 / 3} \mathrm{R}$ binding in $\mathrm{CP}$, NAC, THAL, and MC and higher centroid means of $\mathrm{D}_{2 / 3} \mathrm{R}$ binding in SN/VTA, FC, aHIPP, and pHIPP. Moreover, relative to the second cluster, centroid means of the first one were lower for (1) sitting frequency in the first and fourth time frame, (2) duration of head shoulder motility in the first and second 


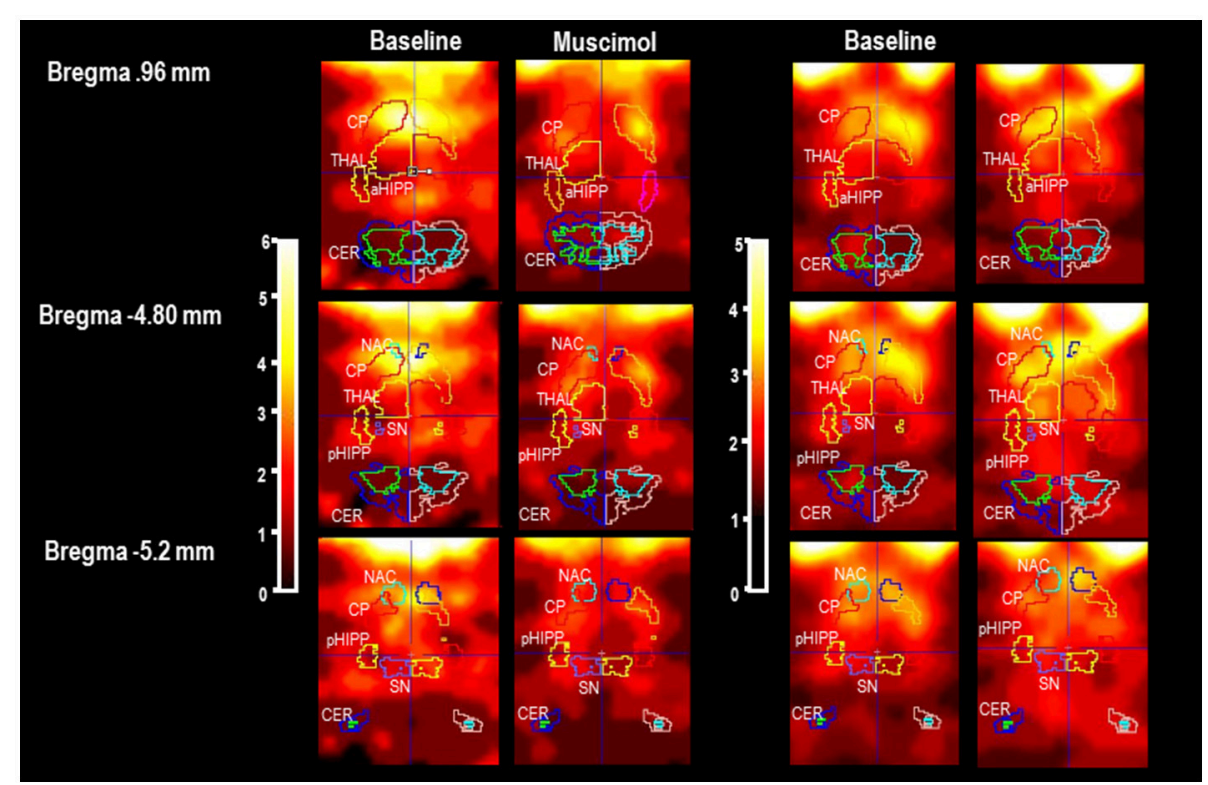

FIGURE 1 | Individual slices at different positions from Bregma (Paxinos and Watson, 2014) in baseline and after pharmacological challenge with 1 mg/kg muscimaol or $1 \mathrm{mg} / \mathrm{kg}$ bicuculline (BAS $\mathrm{MUS}$ and MUS, BAS $\mathrm{BIC}$ and BIC). CP, caudateputamen; NAC, nucleus accumbens; SN, substantia nigra; VTA, ventral tegmental area; THAL, thalamus; PFC, prefrontal cortex; MC, motor cortex; PC, parietal cortex; aHIPP, anterior hippocamus; pHIPP, posterior hippocampus; CER, cerebellum. In the present example, the rat treated with MUS shows a reduction of $\left[{ }^{123}\right.$ ] IBZM accumulation in CP, NAC, THAL, and SN/VTA. The rat treated with BIC shows a slight elevation of $\left[{ }^{123}\right.$ I]IBZM accumulation in CP and THAL.

time frame, and (3) sitting duration in the first, second, fourth, fifth, and sixth time frame, but higher for (1) sitting duration in the third time frame, (2) sitting frequency in the second, third, fifth, and sixth time frame, (3) grooming duration and grooming frequency in the fourth, fifth, and sixth time frame, (4) traveled distance, ambulation duration, and ambulation frequency, duration of head-shoulder motility in the second, third, fourth, fifth, and sixth time frame, and (5) rearing duration, rearing frequency, and frequency of head-shoulder motility in all time frames.

\section{DISCUSSION}

\section{$D_{2 / 3} R$ Binding}

Pre-treatment with the $\mathrm{GABA}_{\mathrm{A}} \mathrm{R}$ agonist MUS in a dose of 1 $\mathrm{mg} / \mathrm{kg}$ significantly reduced $\mathrm{D}_{2 / 3} \mathrm{R}$ binding in $\mathrm{CP}(-17 \%)$, NAC $(-20 \%)$, pHIPP $(-19 \%)$, SN/VTA $(-22 \%)$, and THAL $(-20 \%)$. In contrast, the $\mathrm{GABA}_{\mathrm{A}} \mathrm{R}$ antagonist $\mathrm{BIC}$ in a dose of $1 \mathrm{mg} / \mathrm{k}$ increased $\mathrm{D}_{2 / 3} \mathrm{R}$ binding in $\mathrm{CP}(+8 \%)$ and THAL $(+17 \%)$.

Former investigations have shown that MUS injections into VTA (Klitenick et al., 1992) and NAC (Yoshida et al., 1997; Aono et al., 2008) elevated DA concentrations in these regions. Moreover, MUS increased neostriatal and intranigral DA levels when applied into the SN (Santiago and Westerink, 1992) and into the GP (Cobb and Abercrombie, 2002, 2003). In a precedent study, we had presented first evidence that MUS also after systemic application elevated neostriatal DA levels, leading to a competition between endogenous DA and the exogenous radioligand and a subsequent reduction of radioligand binding to the neostriatal $\mathrm{D}_{2} \mathrm{R}$-like subtype (Nikolaus et al., 2017). The present analysis of these imaging data, using MRI overlays additionally yielded evidence of diminished $\mathrm{D}_{2 / 3} \mathrm{R}$ binding in NAC, THAL, SN/VTA, and pHIPP, reflecting increased availability of DA also in these regions.

Former in vivo microdialysis studies have shown elevated DA levels in CP (Smolders et al., 1995 and NAC (Yan, 1999; Aono et al., 2008) upon administration of BIC into these regions. Furthermore, BIC augmented DA concentrations in the CP, when injected into PFC (Karreman and Moghaddam, 1996; Matsumoto et al., 2003) and SN (Santiago and Westerink, 1992; Westerink et al., 1992) and in the NAC, when injected into the VTA (Ikemoto et al., 1997). This is contrasted by the results of our in vivo imaging study, which revealed increased $\mathrm{D}_{2 / 3} \mathrm{R}$ binding in $\mathrm{CP}$ and THAL upon systemic challenge with BIC, indicating decrements of synaptic DA in these regions. This disagreement, firstly, may be due to the applied dose, which, in the present study $(2.7 \mathrm{mM})$ was considerably higher than in the precedent investigations (10-100 $\mu \mathrm{M}$; Santiago and Westerink, 1992; Westerink et al., 1992; Smolders et al., 1995; Karreman and Moghaddam, 1996; Ikemoto et al., 1997; Yan, 1999; Matsumoto et al., 2003; Aono et al., 2008). A second reason may be the fact, that in the present study the pharmacological challenges were administered systemically in contrast to the localized injection in the other investigations. It may be inferred that the simultaneous targeting of all regions expressing $\mathrm{GABA}_{\mathrm{A}} \mathrm{R}$ binding sites may have influenced the GABAergic (and DAergic) afferents and efferents, regulating nigral, tegmental, striatal, thalamic, and cortical function differently from the localized approach in the in vivo microdialysis studies. 


\section{Muscimol}

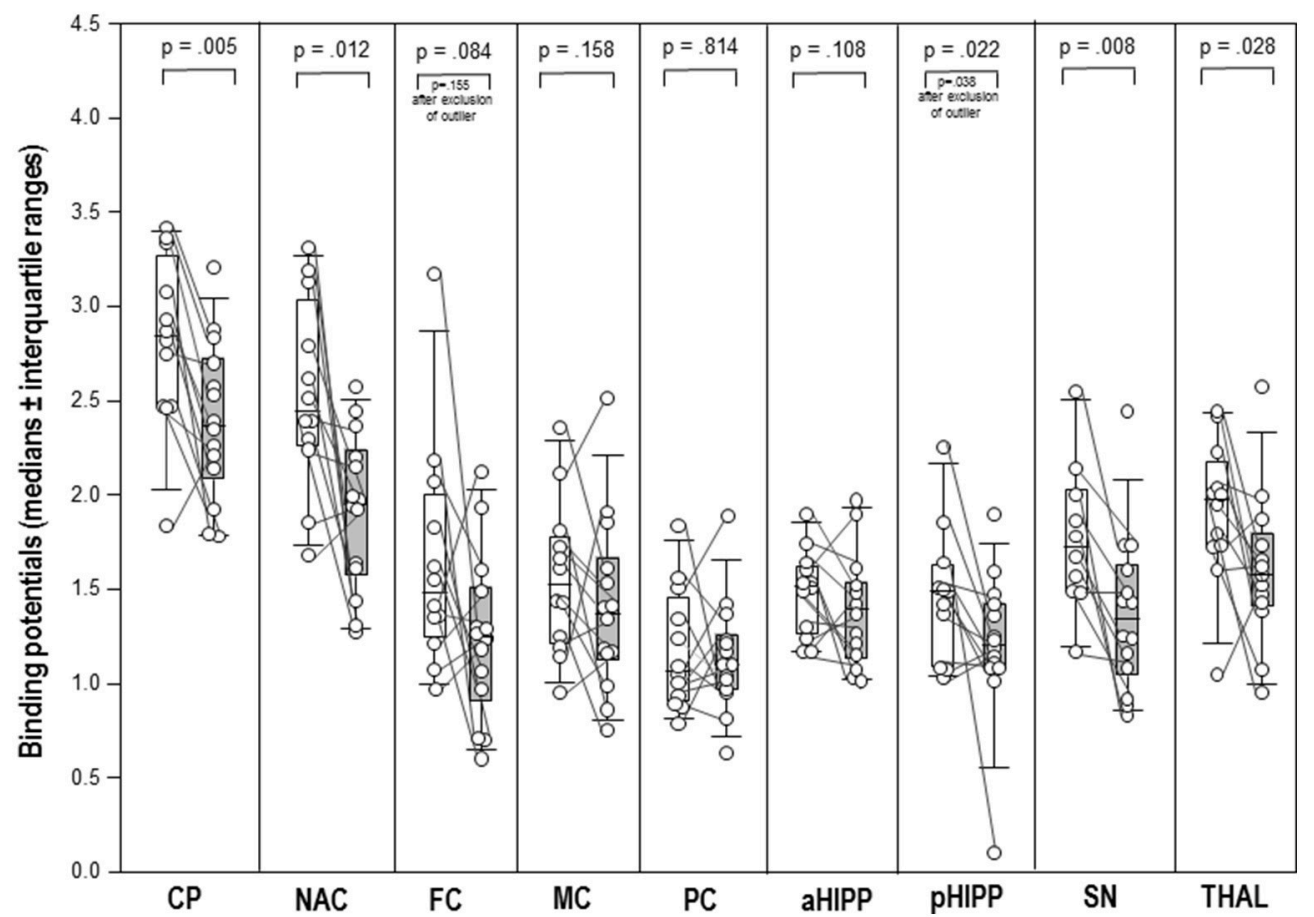

FIGURE 2 | Binding potentials in baseline (white) and after challenge with 1 mg/kg muscimol (gray). Rendered are medians and 25-/75- (boxes) and 9-/95-quartiles (whiskers). The circles represent the individual animals. For significant between-group differences, the respective $p$-values are given (Wilcoxon signed rank test for paired samples, two-tailed, $\alpha=0.05$ ).

In the present study, systemic application of the $\mathrm{GABA}_{\mathrm{A}} \mathrm{R}$ agonist MUS reduced $\mathrm{D}_{2 / 3} \mathrm{R}$ binding in striatum (CP, NAC), THAL, SN/VTA, and pHIPP, reflecting increased availability of $\mathrm{DA}$ in these regions. The $\mathrm{D}_{2} \mathrm{R}$ has two interconvertible binding states for DA, which are referred to as high-affinity (Gprotein-coupled) and low-affinity (G-protein-uncoupled) state (De Lean et al., 1982). To our knowledge, the individual affinities of $\left[{ }^{123} \mathrm{I}\right] \mathrm{IBZM}$ for the high- and the low-affinity $\mathrm{D}_{2} \mathrm{R}$ configuration have not yet been determined. However, studies on $\left[{ }^{11} \mathrm{C}\right]$ raclopride- $\mathrm{a}$ further $\mathrm{D}_{2} \mathrm{R}$ antagonistic benzamide analog widely used for the assessment of $\mathrm{D}_{2} \mathrm{R}$ binding and competion with endogenous DA (Laruelle, 2000)-have shown similar affinities for both types of $\mathrm{D}_{2}$ Rs (Seneca et al., 2006). From this may be inferred that also [ $\left.{ }^{123} \mathrm{I}\right] \mathrm{IBZM}$ binds to $\mathrm{D}_{2} \mathrm{R}$-like binding sites in both configurations and that the regional BPs obtained in the present investigation may be considered to reflect the regional densities of $\mathrm{D}_{2 / 3}$ Rs as such, irrespective of the individual contributions of either affinity state. This not only holds for the BPs in BAS, but also for BPs obtained after challenge with either MUS or BIC, and exempts us from the necessity to differentiate between the individual effects exerted by $\mathrm{D}_{2 / 3}$ Rs in the highand in the low-affinity configuration. With this simplification in mind, the following actions may be hypothesized to occur in the individual brain regions: firstly, within the neostriatal microcircuits (Groves, 1983), the $\mathrm{GABA}_{\mathrm{A}} \mathrm{R}$ agonist action of
MUS can be assumed to lead to a decline of DA efflux. In the DAergic system, DA concentrations undergo regulation by autoreceptors of the $\mathrm{D}_{2} \mathrm{R}$ subtype, which are situated at the presynaptic terminal (Langer, 1974). Consequently, the decrement of striatal DA efflux elicited by MUS is likely to diminish DA binding to presynaptic $\mathrm{D}_{2}$ autoreceptors, leading to a reduction of feedback inhibition, subsequent elevation of DA efflux and the observed reduction of radioligand binding to the $\mathrm{D}_{2 / 3} \mathrm{R}$ in the CP.

The increased $\mathrm{GABA}_{\mathrm{A}} \mathrm{R}$ agonistic action in the CP can be inferred to augment the inhibition of the $\mathrm{SN}$ via the direct pathway. The same effect is exerted by GABAergic thalamonigral and DAergic striatonigral efferents (the latter via inhibitory $\mathrm{D}_{2 / 3} \mathrm{R}$ binding sites). The consequence of both GABAergic and DAergic inhibition is the decrease of nigral DA levels and the subsequent reduction of inhibitory $\mathrm{D}_{2}$ autoreceptor action. Via the indirect pathway, the $\mathrm{SN}$ is disinhibited, which-together with the increased input of excitatory striatonigral efferents (via $\mathrm{D}_{1} \mathrm{R}$ binding sites) and the mentioned decline of $\mathrm{D}_{2}$ autoreceptor action-can be hypothesized to cause the net increase of nigral DA reflected by the reduction of $D_{2 / 3} \mathrm{R}$ under the present experimental conditions.

The increased $\mathrm{GABA}_{\mathrm{A}} \mathrm{R}$ agonistic action in the indirect pathway disinhibits the THAL. Furthermore, elevated DAergic input from the $\mathrm{CP}$ both disinhibits (via $\mathrm{D}_{2 / 3}$ heteroreceptors) 


\section{Bicuculline}

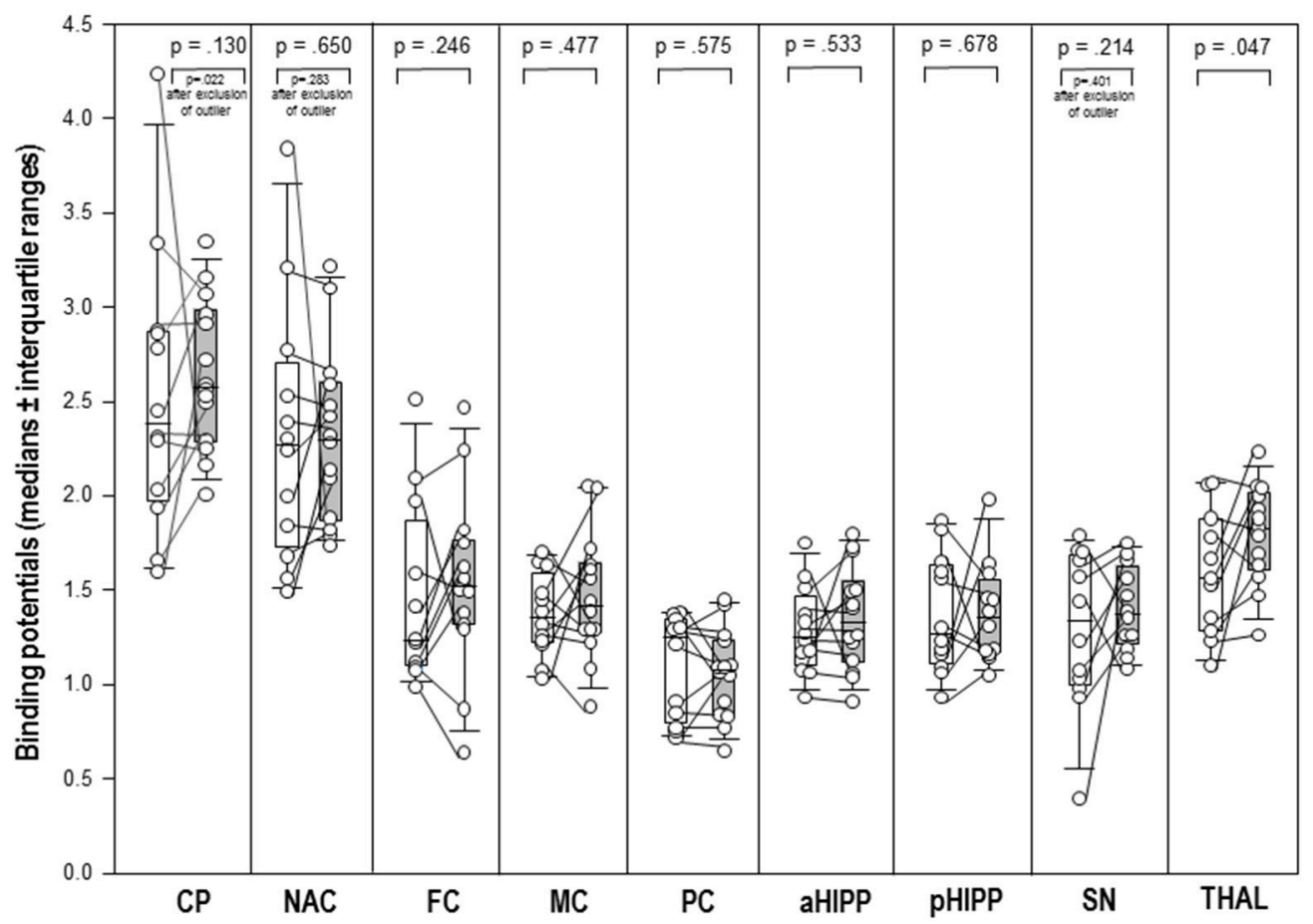

FIGURE 3 | Binding potentials in baseline (white) and after challenge with $1 \mathrm{mg} / \mathrm{kg}$ bicuculline (gray). Rendered are medians and 25-/75- (boxes) and 9-/95-quartiles (whiskers). The circles represent the individual animals. For significant between-group differences, the respective $p$-values are given (Wilcoxon signed rank test for paired samples, two-tailed, $\alpha=0.05)$.

and inhibits (via $\mathrm{D}_{1}$ heteroreceptors) the THAL in the direct and indirect pathway, respectively (Bolam et al., 2000). As indicated by the observed reduction of thalamic $D_{2 / 3} \mathrm{R}$ binding, these effects altogether appear to result in a net increase of thalamic DA.

From the THAL, GLUergic efferents run to the neocortex, which in turn sends GLUergic projections back to the CP (Rouse et al., 2000). Thalamic excitation of the neocortex can be expected to enhance the excitatory input exerted by the descending corticostriatal fibers. The stimulation of striatal N-methyl-Daspartate (NMDA) receptors (Clow and Jhamandas, 1989) likely joins the action of both nigral and striatal $\mathrm{D}_{2}$ autoreceptors in augmenting striatal DA levels in response to the $\mathrm{GABA}_{\mathrm{A}} \mathrm{R}$ agonist action of MUS.

In line with the action of MUS on the CP, leading to an elevated inhibition of the SN, the action of MUS on the NAC may be conceived to enhance the inhibition of the VTA, resulting in a reduction of DA release in the NAC. Again, the diminished DA efflux can be hypothesized to decrease DA binding to presynaptic $\mathrm{D}_{2}$ autoreceptors, leading to a decrease of feedback inhibition, subsequent elevation of DA efflux and the observed reduction of $\mathrm{D}_{2 / 3} \mathrm{R}$ binding in the NAC.

Moreover, elevated $\mathrm{GABA}_{\mathrm{A}} \mathrm{R}$ agonist action in the NAC can be assumed to increase the inhibition of the GP, leading to disinhibition of the THAL. This likely adds to the increased
GABAergic and DAergic action in the indirect and direct pathways, respectively, causing a net increase of thalamic DA and the observed reduction of thalamic $\mathrm{D}_{2 / 3} \mathrm{R}$ binding.

The NAC receives inhibitory GABAergic and DAergic efferents from the PFC (Lee et al., 2014) and the THAL (Hara et al., 1989), respectively. The increase of DA in the THAL probably acts jointly with the inhibition of VTA and NAC to reduce DA levels in the latter region, leading to the decrease of feedback inhibition and subsequent elevation of DA efflux hypothesized to underlie the observed decline of $\mathrm{D}_{2 / 3} \mathrm{R}$ binding.

The HIPP receives DAergic neurons originating in the VTA (Nazari-Serenjeh et al., 2011). Hence, the MUS-induced inhibition of the VTA is likely to diminish the DA release in the HIPP, again resulting in reduced feedback inhibition, subsequent enhancement of DA release, and the observed decline of radioligand binding to the $\mathrm{D}_{2 / 3} \mathrm{R}$ in the pHIPP. The HIPP sends GLUergic efferents to the NAC (Nazari-Serenjeh et al., 2011), with the stimulation of NMDA receptors likely joining the action of $\mathrm{D}_{2}$ autoreceptors in augmenting DA levels in the NAC and subsequently also in the THAL.

In the present study, systemic application of the $\mathrm{GABA}_{\mathrm{A}} \mathrm{R}$ agonist $\mathrm{BIC}$ increased $\mathrm{D}_{2 / 3} \mathrm{R}$ binding in $\mathrm{CP}$ and THAL, reflecting decreased availability of DA in these regions. Firstly, it may be hypothesized that, within the microcircuits in the $\mathrm{CP}$, the $\mathrm{GABA}_{\mathrm{A}} \mathrm{R}$ antagonistic action elicited an increase of DA efflux, 
TABLE 1 | Significant positive and negative correlations $(0.0001 \leq p \leq 0.051)$ between $\mathrm{D}_{2 / 3} \mathrm{R}$ binding in $\mathrm{CP}$, caudateputamen; $\mathrm{NAC}$, nucleus accumbens; THAL, thalamus; SNNTA, substantia nigra/ventral tegmental area; FC, frontal cortex; MC, motor cortex; PC, parietal cortex; aHIPP, anterodorsal hippocampus; pHIPP, posterior hippocampus; and behavioral parameters in the individual time frames after challenge with $1 \mathrm{mg} / \mathrm{kg}$ muscimol (MUS) or $1 \mathrm{mg} / \mathrm{kg}$ bicuculline (BIC).

\begin{tabular}{|c|c|c|c|c|c|c|c|c|c|c|c|c|c|c|c|c|c|c|}
\hline \multirow{2}{*}{$\begin{array}{l}\text { Behavioral } \\
\text { parameter }\end{array}$} & \multicolumn{2}{|c|}{ CP } & \multicolumn{2}{|c|}{ NAC } & \multicolumn{2}{|c|}{ THAL } & \multicolumn{2}{|c|}{ SN/VTA } & \multicolumn{2}{|c|}{ FC } & \multicolumn{2}{|c|}{ MC } & \multicolumn{2}{|c|}{ PC } & \multicolumn{2}{|c|}{ aHIPP } & \multicolumn{2}{|c|}{ pHIPP } \\
\hline & MUS & BIC & MUS & BIC & MUS & BIC & MUS & BIC & MUS & BIC & MUS & BIC & MUS & BIC & MUS & BIC & MUS & BIC \\
\hline \multicolumn{19}{|c|}{ Traveled distance } \\
\hline $\min 1-5$ & & & & & 0.610 & & & & & & & & & & & & & \\
\hline \multicolumn{19}{|l|}{$\min 6-10$} \\
\hline \multicolumn{19}{|l|}{$\min 11-15$} \\
\hline $\min 16-20$ & 0.552 & & & & & & & & & & & & & & & & & \\
\hline \multicolumn{19}{|l|}{$\min 21-25$} \\
\hline $\min 26-30$ & 0.556 & & & & & & 0.658 & & & & & & & & & & & 0.580 \\
\hline
\end{tabular}

Ambulation

duration

$\min 1-5$

$\min 6-10$

$\min 11-15$

$\min 16-20$

min 21-25

$\min 26-30$

Ambulation

frequency

$\min 1-5$

$\min 6-10$

$\min 11-15$

$\min 16-20$

min 21-25

$\min 26-30$

Sitting duration

$\min 1-5$

$\min 6-10$

$\min 11-15$

min 16-20

$\min 21-25$

min 26-30

0.543

Sitting frequency

$\min 1-5$

$\min 6-10$

$\min 11-15$

$\min 16-20$

$\min 21-25$

min 26-30

$-0.574 \quad-0.644$

$-0.646$

0.579

Rearing duration

$\min 1-5$

$\min 6-10$

$\min 11-15$

min 16-20

min 21-25

$\min 26-30$

Rearing frequency

min 1-5

0.689

0.665

0.568

$\min 6-10$

$\min 11-15$

min 16-20

$\min 21-25$

$\min 26-30$

$\begin{array}{ll}0.529 & 0.576\end{array}$

0.542

$0.663 \quad 0.581$


TABLE 1 | Continued

\begin{tabular}{|c|c|c|c|c|c|c|c|c|c|c|c|c|c|c|c|c|c|c|}
\hline \multirow{2}{*}{$\begin{array}{l}\text { Behavioral } \\
\text { parameter }\end{array}$} & \multicolumn{2}{|c|}{$\mathrm{CP}$} & \multicolumn{2}{|c|}{ NAC } & \multicolumn{2}{|c|}{ THAL } & \multicolumn{2}{|c|}{ SN/VTA } & \multicolumn{2}{|c|}{ FC } & \multicolumn{2}{|c|}{ MC } & \multicolumn{2}{|c|}{ PC } & \multicolumn{2}{|c|}{ aHIPP } & \multicolumn{2}{|c|}{ pHIPP } \\
\hline & MUS & $\mathrm{BIC}$ & MUS & BIC & MUS & BIC & MUS & BIC & MUS & BIC & MUS & BIC & MUS & BIC & MUS & BIC & MUS & BIC \\
\hline $\begin{array}{l}\text { Duration of } \\
\text { head-shoulder } \\
\text { motility } \\
\text { min } 1-5 \\
\text { min } 6-10 \\
\min 11-15 \\
\min 16-20 \\
\min 21-25 \\
\min 26-30\end{array}$ & & & 0.534 & & & & -0.583 & & & & 0.565 & & & & & & & 0.727 \\
\hline $\begin{array}{l}\text { Frequency of } \\
\text { head-shoulder } \\
\text { motility } \\
\text { min } 1-5 \\
\text { min } 6-10 \\
\min 11-15 \\
\min 16-20 \\
\min 21-25 \\
\min 26-30\end{array}$ & $\begin{array}{l}-0.538 \\
0.521 \\
0.561\end{array}$ & & 0.676 & -0.776 & & & 0.626 & & 0.738 & & 0.703 & & & & & -0.583 & 0.546 & 0.643 \\
\hline $\begin{array}{l}\text { Grooming dure } \\
\min 1-5 \\
\min 6-10 \\
\min 11-15 \\
\min 16-20 \\
\min 21-25 \\
\min 26-30\end{array}$ & & & -0.619 & 0.525 & & & & & -0.575 & & & & & & & & -0.524 & \\
\hline $\begin{array}{l}\text { Grooming } \\
\text { frequency } \\
\text { min } 1-5 \\
\min 6-10 \\
\min 11-15 \\
\min 16-20 \\
\min 21-25 \\
\min 26-30\end{array}$ & -0.722 & & -0.740 & & & & & & & & -0.534 & & & & -0.616 & & -0.714 & \\
\hline
\end{tabular}

Positive and negative correlations are marked in red and blue, respectively.

which is compensated by an enhancement of feedback inhibition and subsequent reduction of DA levels, as indicated in the present study by the elevation of $\mathrm{D}_{2 / 3} \mathrm{R}$ binding in the $\mathrm{CP}$.

In vivo imaging studies did not show alterations of $\mathrm{D}_{2 / 3} \mathrm{R}$ binding (and DA) in SN/VTA and NAC. Therefore, actions of $\mathrm{BIC}$ on thalamic DA via the NAC can be dismissed. It may be inferred, however, that the increased $\mathrm{GABA}_{\mathrm{A}} \mathrm{R}$ antagonistic action in the indirect pathway leads to an inhibition of the THAL. Furthermore, also the BIC-induced reduction of DAergic input from the CP decreases both thalamic inhibition (via $\mathrm{D}_{2 / 3}$ heteroreceptors) and excitation (via $\mathrm{D}_{1}$ heteroreceptors) in the direct and indirect pathway, respectively. Altogether, these effects may be assumed to result in a net decrease of thalamic DA and the observed elevation of thalamic $\mathrm{D}_{2 / 3} \mathrm{R}$ binding.

\section{Rat Behavior}

Imaging and behavioral data obtained after MUS can be grouped into two clusters with the first one characterized by lower $\mathrm{D}_{2 / 3} \mathrm{R}$ binding in CP, NAC, THAL, and FC and higher $\mathrm{D}_{2 / 3} \mathrm{R}$ binding in SN/VTA, MC, PC, aHIPP, and pHIPP and the second one displaying the opposite. Moreover, the animals of the first cluster showed less motor/exploratory behaviors and more sitting and grooming, whereas the animals of the second cluster exhibited more motor/exploratory activity and less sitting and grooming. Hence, the cluster analysis implies an inverse relationship between DA levels in the nigrostriatal/mesolimbic system and motor/exploratory activity after $\mathrm{GABA}_{\mathrm{A}} \mathrm{R}$ agonistic treatment. In addition, correlation analysis revealed that, after MUS, lower $\mathrm{D}_{2 / 3} \mathrm{R}$ binding (and higher $\mathrm{DA}$ ) throughout the entire DAergic system (CP, NAC, SN/VTA, FC, MC, aHIPP, and pHIPP) was associated with a reduction of motor/exploratory parameters in the second half of the testing time and an increase of sitting and grooming primarily from 11 to $15 \mathrm{~min}$. From this, we infer that, after systemic MUS, DA concentrations in the nigrostriatal and mesolimbic system started to rise around $11 \mathrm{~min}$ post-injection. Furthermore, the reductions of $\mathrm{D}_{2 / 3} \mathrm{R}$ binding in the imaging studies indicate that the synaptic DA levels were still elevated in 75-135 min after MUS challenge. 
TABLE 2 | Centroid means of $D_{2 / 3} R$ binding in CP, caudateputamen; NAC, nucleus accumbens; THAL, thalamus; SN/NTA, substantia nigra/ventral tegmental area; FC, frontal cortex; MC, motor cortex; PC, parietal cortex; aHIPP, anterodorsal hippocampus; pHIPP, posterior hippocampus; as well as traveled distance and ambulation and frequency of ambulation, sitting, rearing, head-shoulder motility, and grooming in the individual time frames (min 1-5, 6-10, 11-15, 16-20, 21-25, and 26-30) in rats pre-treated with $1 \mathrm{mg} / \mathrm{kg}$ muscimol (MUS) or $1 \mathrm{mg} / \mathrm{kg}$ biculline (BIC) after Z-transformation of the individual data.

\begin{tabular}{|c|c|c|c|c|c|}
\hline \multirow[b]{2}{*}{ Variable } & \multirow[b]{2}{*}{ Time frame } & \multicolumn{2}{|c|}{ MUS } & \multicolumn{2}{|c|}{ BIC } \\
\hline & & C1 & C2 & C1 & C2 \\
\hline $\mathrm{D}_{2 / 3} \mathrm{R}-\mathrm{CP}$ & & -0.143 & 0.184 & -0.335 & 0.201 \\
\hline$D_{2 / 3} R-N A C$ & & -0.298 & 0.384 & -0.270 & 0.162 \\
\hline $\mathrm{D}_{2 / 3} \mathrm{R}$-THAL & & -0.045 & 0.058 & -0.082 & 0.049 \\
\hline $\mathrm{D}_{2 / 3} \mathrm{R}-\mathrm{SN} / \mathrm{NTA}$ & & 0.012 & -0.015 & 0.552 & -0.331 \\
\hline $\mathrm{D}_{2 / 3} \mathrm{R}-\mathrm{FC}$ & & -0.035 & 0.046 & 0.143 & -0.086 \\
\hline $\mathrm{D}_{2 / 3} \mathrm{R}-\mathrm{MC}$ & & 0.034 & -0.045 & -0.226 & 0.136 \\
\hline $\mathrm{D}_{2 / 3} \mathrm{R}-\mathrm{PC}$ & & 0.123 & -0.158 & 0.437 & -0.262 \\
\hline $\mathrm{D}_{2 / 3} \mathrm{R}-\mathrm{aHIPP}$ & & 0.021 & -0.027 & 0.444 & -0.267 \\
\hline $\mathrm{D}_{2 / 3} \mathrm{R}-\mathrm{pHIPP}$ & & 0.103 & -0.132 & 0.694 & -0.416 \\
\hline Traveled distance & $\min 1-5$ & -0.510 & 0.656 & 0.318 & -0.191 \\
\hline Ambulation duration & $\min 1-5$ & -0.429 & 0.552 & 0.183 & -110 \\
\hline Ambulation frequency & $\min 1-5$ & -0.490 & 0.630 & 0.260 & -0.156 \\
\hline Sitting duration & $\min 1-5$ & 0.486 & -0.624 & -0.332 & 0.199 \\
\hline Sitting frequency & $\min 1-5$ & 0.516 & -0.664 & -0.060 & 0.036 \\
\hline Rearing duration & $\min 1-5$ & -0.576 & 0.741 & 0.547 & -0.328 \\
\hline Rearing frequency & $\min 1-5$ & -0.551 & 0.709 & 0.650 & -0.390 \\
\hline $\begin{array}{l}\text { Head-shoulder motility } \\
\text { duration }\end{array}$ & $\min 1-5$ & -0.203 & 0.261 & -0.214 & 0.129 \\
\hline $\begin{array}{l}\text { Head-shoulder motility } \\
\text { frequency }\end{array}$ & $\min 1-5$ & -0.281 & 0.362 & 0.067 & -0.004 \\
\hline Grooming duration & $\min 1-5$ & 0.071 & -0.091 & -0.246 & 0.148 \\
\hline Grooming frequency & $\min 1-5$ & 0.175 & -0.225 & -0.070 & 0.042 \\
\hline Traveled distance & $\min 6-10$ & -0.539 & 0.693 & 0.431 & -0.259 \\
\hline Ambulation duration & $\min 6-10$ & -0.420 & 0.540 & 0.509 & -0.305 \\
\hline Ambulation frequency & $\min 6-10$ & -0.562 & 0.723 & 0.456 & -0.273 \\
\hline Sitting duration & $\min 6-10$ & 0.538 & -0.692 & -0.117 & 0.070 \\
\hline Sitting frequency & $\min 6-10$ & 0.510 & -0.656 & 0.223 & -0.134 \\
\hline Rearing duration & $\min 6-10$ & -0.546 & 0.702 & 0.043 & -0.026 \\
\hline Rearing frequency & $\min 6-10$ & -0.563 & 0.724 & 0.250 & -0.150 \\
\hline $\begin{array}{l}\text { Head-shoulder motility } \\
\text { duration }\end{array}$ & $\min 6-10$ & -0.559 & 0.719 & 0.384 & -0.231 \\
\hline $\begin{array}{l}\text { Head-shoulder motility } \\
\text { frequency }\end{array}$ & $\min 6-10$ & -0.590 & 0.758 & 0.642 & -0.385 \\
\hline Grooming duration & $\min 6-10$ & 0.278 & -0.358 & -0.332 & 0.199 \\
\hline Grooming frequency & $\min 6-10$ & 0.045 & -0.058 & -0.323 & 0.194 \\
\hline Traveled distance & $\min 11-15$ & -0.278 & 0.358 & 0.783 & -0.470 \\
\hline Ambulation duration & $\min 11-15$ & -0.273 & 0.351 & 0.727 & -0.436 \\
\hline Ambulation frequency & $\min 11-15$ & -0.332 & 0.426 & 0.900 & -0.540 \\
\hline Sitting duration & $\min 11-15$ & 0.374 & -0.481 & 0.106 & -0.064 \\
\hline Sitting frequency & $\min 11-15$ & 0.131 & -0.168 & 0.504 & -0.303 \\
\hline Rearing duration & $\min 11-15$ & -0.426 & 0.547 & 0.467 & -0.280 \\
\hline Rearing frequency & $\min 11-15$ & -0.234 & 0.300 & 0.621 & -0.372 \\
\hline $\begin{array}{l}\text { Head-shoulder motility } \\
\text { duration }\end{array}$ & $\min 11-15$ & -0.632 & 0.812 & 0.782 & -0.469 \\
\hline
\end{tabular}

(Continued)
TABLE 2 | Continued

\begin{tabular}{|c|c|c|c|c|c|}
\hline \multirow[b]{2}{*}{ Variable } & \multirow[b]{2}{*}{ Time frame } & \multicolumn{2}{|c|}{ MUS } & \multicolumn{2}{|c|}{ BIC } \\
\hline & & C1 & C2 & C1 & C2 \\
\hline $\begin{array}{l}\text { Head-shoulder motility } \\
\text { frequency }\end{array}$ & $\min 11-15$ & -0.522 & 0.671 & 1.014 & -0.608 \\
\hline Grooming duration & $\min 11-15$ & 0.398 & -0.512 & -0.826 & 0.496 \\
\hline Grooming frequency & $\min 11-15$ & 0.155 & -0.199 & -0.499 & 0.299 \\
\hline Traveled distance & $\min 16-20$ & -0.294 & 0.378 & 0.299 & -0.179 \\
\hline Ambulation duration & $\min 16-20$ & -0.350 & 0.450 & 0.305 & -0.183 \\
\hline Ambulation frequency & $\min 16-20$ & -0.340 & 0.437 & 0.257 & -0.154 \\
\hline Sitting duration & $\min 16-20$ & 0.277 & -0.356 & -0.386 & 0.232 \\
\hline Sitting frequency & $\min 16-20$ & 0.266 & -0.342 & -0.066 & 0.039 \\
\hline Rearing duration & $\min 16-20$ & -0.408 & 0.525 & 0.058 & -0.035 \\
\hline Rearing frequency & $\min 16-20$ & -0.183 & 0.235 & 0.085 & -0.051 \\
\hline $\begin{array}{l}\text { Head-shoulder motility } \\
\text { duration }\end{array}$ & $\min 16-20$ & -0.224 & 0.288 & 0.342 & -0.205 \\
\hline $\begin{array}{l}\text { Head-shoulder motility } \\
\text { frequency }\end{array}$ & $\min 16-20$ & -0.225 & 0.290 & 0.309 & -0.186 \\
\hline Grooming duration & $\min 16-20$ & 0.005 & -0.007 & 0.281 & -0.168 \\
\hline Grooming frequency & $\min 16-20$ & 0.103 & -0.132 & 0.628 & -0.377 \\
\hline Traveled distance & $\min 21-25$ & 0.172 & -0.221 & 0.412 & -0.259 \\
\hline Ambulation duration & $\min 21-25$ & 0.245 & -0.315 & 0.582 & -0.349 \\
\hline Ambulation frequency & $\min 21-25$ & 0.185 & -0.238 & 0.412 & -0.247 \\
\hline Sitting duration & $\min 21-25$ & -0.148 & 0.187 & -0.622 & 0.373 \\
\hline Sitting frequency & $\min 21-25$ & -0.146 & 0.187 & 0.049 & -0.029 \\
\hline Rearing duration & $\min 21-25$ & -0.016 & 0.020 & 0.356 & -0.214 \\
\hline Rearing frequency & $\min 21-25$ & -0.040 & 0.051 & 0.380 & -0.229 \\
\hline $\begin{array}{l}\text { Head-shoulder motility } \\
\text { duration }\end{array}$ & $\min 21-25$ & -0.045 & 0.058 & 0.297 & -0.178 \\
\hline $\begin{array}{l}\text { Head-shoulder motility } \\
\text { frequency }\end{array}$ & 5 & 0.189 & 0.243 & 0.382 & -0 \\
\hline Grooming duration & $\min 21-25$ & 0.219 & -0.281 & 0.475 & -0.285 \\
\hline Grooming frequency & $\min 21-25$ & 0.276 & -0.354 & 0.525 & -0.315 \\
\hline Traveled distance & $\min 26-30$ & -0.359 & 0.461 & 1.054 & -0.633 \\
\hline Ambulation duration & $\min 26-30$ & -0.329 & 0.423 & 1.070 & -0.642 \\
\hline Ambulation frequency & $\min 26-30$ & -0.336 & 0.432 & 0.964 & -0.578 \\
\hline Sitting duration & $\min 26-30$ & 0.216 & -0.277 & -0.857 & 0.514 \\
\hline Sitting frequency & $\min 26-30$ & 0.033 & 0.461 & 0.486 & -0.291 \\
\hline Rearing duration & $\min 26-30$ & -0.376 & 0.483 & 0.850 & -0.510 \\
\hline Rearing frequency & $\min 26-30$ & -0.361 & 0.464 & 0.922 & -0.553 \\
\hline $\begin{array}{l}\text { Head-shoulder motility } \\
\text { duration }\end{array}$ & $\min 26-30$ & -0.347 & 0.446 & 0.880 & -0.528 \\
\hline $\begin{array}{l}\text { Head-shoulder motility } \\
\text { frequency }\end{array}$ & $\min 26-30$ & -0.288 & 0.371 & 0.984 & -0.590 \\
\hline Grooming duration & $\min 26-30$ & 0.364 & -0.468 & 0.489 & -0.294 \\
\hline Grooming frequency & $\min 26-30$ & 0.015 & -0.019 & 0.523 & -0.314 \\
\hline
\end{tabular}

For imaging and behavioral data obtained after BIC, the cluster analysis yielded two clusters with the first one characterized by lower $\mathrm{D}_{2 / 3} \mathrm{R}$ binding in $\mathrm{CP}, \mathrm{NAC}$, THAL, and $\mathrm{MC}$ and higher $\mathrm{D}_{2 / 3} \mathrm{R}$ binding in SN/VTA, FC, aHIPP, and pHIPP and the second one displaying the opposite. Moreover, the animals of the first cluster showed less sitting, but more motor/exploratory behaviors as well as grooming throughout the 
testing time, whereas those of the second cluster exhibited more sitting and less motor/exploratory activity and grooming. Thus, interestingly, after $\mathrm{GABA}_{\mathrm{A}} \mathrm{R}$ antagonistic treatment, leading to decreased DA in CP and THAL but normal DA in the other brain regions, a direct relationship emerges between DA concentration in the nigrostriatal/mesolimbic system and motor/exploratory activity.

Yet, the correlation analysis revealed an association between lower $\mathrm{D}_{2 / 3} \mathrm{R}$ binding (and higher $\mathrm{DA}$ ) throughout the nigrostriatal/mesolimbic system (CP, NAC, THAL, MC, and aHIPP) and more sitting and head-shoulder motility as well as less traveled distance, and rearing primarily during the first $5 \mathrm{~min}$ of testing time. This, for one, indicates that the $\mathrm{GABA}_{\mathrm{A}} \mathrm{R}$ antagonist elicited an almost immediate decline of synaptic DA concentrations, which, in NAC and THAL, was still visible at the time of in vivo imaging studies, and which is reflected by the immediate reduction of motor/exploratory behaviors. Secondly, however, it seems that the association between nigrostriatal/mesolimbic DA and motor/exploratory behaviors is different for generally high (as after L-DOPA Nikolaus et al., 2016 or MUS) and generally low or normal levels of DA (as after BIC) with the former inversely and the latter directly related to motor/exploratory activity. Further in vivo imaging studies of $\mathrm{D}_{2 / 3} \mathrm{R}$ binding after increasing doses of L-DOPA, MUS, and $\mathrm{BIC}$ are required to gain more information on this regulation mechanism, which is likely to involve tight region-specific $\mathrm{D}_{2}$ autoreceptor action.

\section{Appraisal}

Against the present findings the objection can be raised that $\mathrm{D}_{2 / 3} \mathrm{R}$ SPECT and MR images were not obtained on the same rats, which may have led to misalignments not only between $\mathrm{D}_{2 / 3} \mathrm{R}$ SPECT and MRI of individual animals, but also between $\mathrm{D}_{2 / 3} \mathrm{R}$ SPECT and the standard Paxinos rat brain MRI. However, the BPs obtained for the $\mathrm{CP}$ in the present study $\left(\mathrm{BAS}_{\mathrm{MUS}}\right.$ : 2.845, MUS: 2.37) were in agreement with the previous mean neostriatal equilibrium ratios $\left(\mathrm{V}_{3}{ }^{\prime \prime}\right)$ of $1.818\left(\mathrm{BAS}_{\mathrm{MUS}}\right)$ and 1.397 (MUS), corresponding to BPs of 2.818 and 2.397, respectively (Nikolaus et al., 2017). Also after BIC, the BPs obtained for the $\mathrm{CP}\left(\mathrm{BAS}_{\mathrm{BIC}}\right.$ : 2.380, BIC: 2.575) were consistent with the fromer findings $\left(\mathrm{BAS}_{\mathrm{BIC}}: \mathrm{V}_{3}{ }^{“}=1.532, \mathrm{BP}=2.532\right.$; $\mathrm{BIC}: \mathrm{V}_{3}$ “ $=1.646, \mathrm{BP}=2.646$; Nikolaus et al., 2017), which argues in favor of the present method. Although also the previous data had indicated an increase of neostriatal $\mathrm{D}_{2 / 3} \mathrm{R}$ binding after $\mathrm{BIC}$, this difference had not reached statistical significance. It may be argued, thus, that the MRI-based mode of analysis is superior to the former method of defining a small VOI around the neostriatal hot spot of maximum radioactivity accumulation, since it allows the definition of exact anatomical VOIs within the striatum. Besides, also the definition of VOIs other than striatal ones is rendered possible, resulting in the present first-time evidence of GABAergic effects on thalamic, nigral/ventral tegmental, and hippocampal DA obtained with in vivo imaging methods.

The maximum VOI diameters are either in the range or beyond the spatial resolution of the employed imaging system. It must be borne in mind, however, that the quantification of $\mathrm{D}_{2 / 3} \mathrm{R}$ binding in those portions of VOIs, which fall short of the full width at half maximum, may be hampered by partial volume effects, leading to underestimations of radioligand accumulations. Another pitfall may be overestimation of radioligand binding due to spill-over from regions with high radioligand accumulation such as the extraorbital Harderian glands to the adjacent VOIs of FC, CP, and NAC, or from the CP to NAC, THAL, and aHIPP. It can be maintained, however, that (semi)quantitative data-also of regions such as NAC, THAL, SN/VTA, and HIPP - are comparable between BAS and challenge in the present study as well as between investigations on other rats perfomed with the same imaging tool (Nikolaus et al., 2011, 2013, 2014a, 2016, 2017). As soon as further imaging studies on $\mathrm{D}_{2} \mathrm{R}$-like binding sites in these regions will be available, it will be interesting to see, in which range the present binding ratios lie in comparison to binding ratios obtained with new-generation SPECT systems.

Dysfunctions of $\mathrm{GABA}_{\mathrm{A}}$ Rs and $\mathrm{D}_{2}$ R-like binding sites have been implied in neuropsychiatric disorders including anxiety disorders and schizophrenia (Nikolaus et al., 2010, 2014b,c). Interestingly, the decline of $\mathrm{GABA}_{\mathrm{A}} \mathrm{R}$ function in anxiety disorders involves the whole nigrostriatal and mesolimbic system, while the function of $\mathrm{D}_{2} \mathrm{R}$-like binding sites is merely impaired in the CP. Contrarily, in schizophrenia, the reduction of $\mathrm{GABA}_{\mathrm{A}} \mathrm{R}$ binding is confined to the neocortex, while $\mathrm{D}_{2} \mathrm{R}$ like binding sites are dysfunctional throughout the nigrostriatal and mesolimbic system. This implies that the emotional and behavioral changes characteristic for the individual diseases are related to regional neurochemic alterations of receptor function. The present study in the rat constitutes an important step toward unraveling the complex interdependencies of behaviors and the neurochemistry of DA and GABA using a two-modality in vivo imaging approach.

\section{CONCLUSION}

Findings indicate direct GABAergic control over synaptic DA levels in the migrostriatal and mesolimbic system in relation to behavioral action. The may be of relevance for neuropsychiatric conditions such as anxiety disorder and schizophrenia, which are characterized by both DAergic and GABAergic dysfunction.

\section{AUTHOR CONTRIBUTIONS}

SN, MADSS, JPH, CA, GA and H-WM: Experimental design; SN, H-JW, AM-L and FW: Performance of imaging and behavioral studies; SN and MB: Evaluation and statistical analysis; $\mathrm{SN}, \mathrm{MB}$, CA, MADSS, JPH, HH, H-WM: Interpreation of findings; SN, H-JW, CA, MADSS, JPH, GA, HH, H-WM: Writing and editing of the manuscript.

\section{ACKNOWLEDGMENTS}

MADSS was supported by a Heisenberg Fellowship SO 1032/51 and EU-FP7 (MC-ITN-In-SENS-ESR7 607616). JPH was supported by Deutsche Forschungsgemeinschaft (Grant: DFG HU 306/27-3). 


\section{SUPPLEMENTARY MATERIAL}

The Supplementary Material for this article can be found online at: https://www.frontiersin.org/articles/10.3389/fnbeh. 2018.00038/full\#supplementary-material

Supplementary Figure I VOI definition on overlays of SPECT images of $\left[{ }^{123}\right.$ ] IBZM binding to the $D_{2} R$ (which had been formerly coregistered with the $\mathrm{MRI}$ of a rat of the same weight), with the standard Paxinos rat brein MRI (Schiffer et al., 2006). CP, caudateputamen; NAC, nucleus accumbens; SN, substantia nigra; VTA, THAL, thalamus; PFC, prefrontal cortex; FC, frontal cortex; MC, motor cortex; PC, parietal cortex; aHIPP, anterior hippocamus; pHIPP, posterior hippocampus; CER, cerebellum.

Supplementary Table | Behavioral data (either the number [n] of behaviors or the time [s], the animals engaged in a specific behavior) obtained for the individual rats after challenge with either $1 \mathrm{mg} / \mathrm{kg}$ muscimol (MUS) or $1 \mathrm{mg} / \mathrm{kg}$ bicuculline $(\mathrm{BIC})$ in the individual time frames.

\section{REFERENCES}

Aono, Y., Saigusa, T., Mizoguchi, N., Iwakami, T., Takada, K., Gionhaku, N., et al. (2008). Role of GABAA receptors in the endomorphin-1-, but not endomorphin-2-, induced dopamine efflux in the nucleus accumbens of freely moving rats. Eur. J. Pharmacol. 580, 87-94. doi: 10.1016/j.ejphar.2007.10.020

Baleydier, C., and Mauguiere, F. (1980). The duality of the cingulate gyrus in monkey. Neuroanatomical study and functional hypothesis. Brain 103, 525-554. doi: 10.1093/brain/103.3.525

Bolam, J. P., Hanley, J. J., Booth, P. A., and Bevan, M. D. (2000).Synaptic organisation of the basal ganglia. J. Anat. 196, 527-542. doi: 10.1046/j.1469-7580.2000.19640527.x

Bouthenet, M. L., Martres, M. P., Sales, N., and Schwartz, J. C. (1987). A detailed mapping of dopamine D-2 receptors in rat central nervous system by autoradiography with [125I]iodosulpride. Neuroscience 20, 117-155. doi: 10.1016/0306-4522(87)90008-X

Cellot, G., and Cherubini, E. (2014). GABAergic signaling as therapeutic target for autism spectrum disorders. Front. Pediatr. 2:70. doi: 10.3389/fped.2014.00070

Clow, D. W., and Jhamandas, K. (1989). Characterization of L-glutamate action on the release of endogenous dopamine from the rat caudate-putamen. J. Pharmacol. Exp. Ther. 248, 722-728.

Cobb, W. S., and Abercrombie, E. D. (2002). Distinct roles for nigral GABA and glutamate receptors in the regulation of dendritic dopamine release under normal conditions and in response to systemic haloperidol. J. Neurosci. 22, 1407-1413.

Cobb, W. S., and Abercrombie, E. D. (2003). Relative involvement of globus pallidus and subthalamic nucleus in the regulation of somatodendritic dopamine release in substantia nigra is dopamine-dependent. Neuroscience 119, 777-786. doi: 10.1016/S0306-4522(03)00071-X

Coimbra, N. C., and Brandao, M. L. (1993). GABAergic nigrocollicular pathways modulate the defensive behaviour elicited by midbrain tectum stimulation. Behav Brain Res. 59, 131-139. doi: 10.1016/0166-4328(93) 90159-N

De Lean, A., Kilpatrick, B. F., and Caron, M. G. (1982). Dopamine receptor of the porcine anterior pituitary gland. Evidence for two affinity states discriminated by both agonists and antagonists. Mol. Pharmacol. 22, 290-297.

Gerfen, C. R. (1984). The neostriatal mosaic: compartmentalization of corticostriatal input and striatonigral output systems. Nature 311, 461-464. doi: $10.1038 / 311461 \mathrm{a} 0$

Gerfen, C. R., Herkenham, M., and Thibault, J. (1987). The neostriatal mosaic: II. Patch- and matrix-directed mesostriatal dopaminergic and non-dopaminergic systems. J. Neurosci. 7, 3915-3934.

Graybiel, A. M., and Ragsdale, C. W. Jr. (1979). Fiber connections of the basal ganglia. Prog. Brain Res. 51, 237-283. doi: 10.1016/S0079-6123(08)61309-6

Groves, P. M. (1983). A theory of the functional organization of the neostriatum and the neostriatal control of voluntary movement. Brain Res. 5, 109-132.

Haase, A., Frahm, J., Matthaei, D., Hänicke, W., and Merboldt, K. D. (1986). FLASH imaging. Rapid NMR imaging using low flip-angle pulses. J. Magn. Reson. 67, 258-266. doi: 10.1016/0022-2364(86)90433-6

Hara, M., Sasa, M., and Takaori, S. (1989). Ventral tegmental area-mediated inhibition of neurons of the nucleus accumbens receiving input from the parafascicular nucleus of the thalamus is mediated by dopamine D1 receptors. Neuropharmacology 28, 1203-1209. doi: 10.1016/0028-3908(89)90212-8

Herkenham, M. (1979). The afferent and efferent connections of the ventromedial thalamic nucleus in the rat. J. Comp. Neurol. 183, 487-517. doi: $10.1002 /$ cne. 901830304

Ichise, M., Meyer, J. H., and Yonekura, Y. (2001). An introduction to PET and SPECT neuroreceptor quantification models. J. Nucl. Med. 42, 755-763.

Ikemoto, S., Kohl, R. R., and McBride, W. J. (1997). GABA(A) receptor blockade in the anterior ventral tegmental area increases extracellular levels of dopamine in the nucleus accumbens of rats. J. Neurochem. 69, 137-143. doi: 10.1046/j.1471-4159.1997.69010137.x

Ishikawa, A., and Nakamura, S. (2006). Ventral hippocampal neurons project axons simultaneously to the medial prefrontal cortex and amygdala in the rat. J. Neurophysiol. 96, 2134-2138. doi: 10.1152/jn.00069. 2006

Jayaraman, A. (1985). Organization of thalamic projections in the nucleus accumbens and the caudate nucleus in cats and its relation with hippocampal and other subcortical afferents. J. Comp. Neurol. 231, 396-420. doi: $10.1002 /$ cne.902310309

Johnson, T. N., Rosvold, H. E., and Mishkin, M. (1968). Projections from behaviorally-defined sectors of the prefrontal cortex to the basal ganglia, septum, and diencephalon of the monkey. Exp. Neurol. 21, 20-34. doi: 10.1016/0014-4886(68)90030-7

Jones, E. G., Coulter, J. D., Burton, H., and Porter, R. (1977). Cells of origin and terminal distribution of corticostriatal fibers arising in the sensory-motor cortex of monkeys. J. Comp. Neurol. 173, 53-80. doi: 10.1002/cne.901730105

Karreman, M., and Moghaddam, B. (1996). The prefrontal cortex regulates the basal release of dopamine in the limbic striatum: an effect mediated by ventral tegmental area. J. Neurochem. 66, 589-598. doi: 10.1046/j.1471-4159.1996.66020589.x

Klitenick, M. A., DeWitte, P., and Kalivas, P. W. (1992). Regulation of somatodendritic dopamine release in the ventral tegmental area by opioids and GABA: an in vivo microdialysis study. J. Neurosci. 12, 2623-2632.

Künzle, H. (1977). Projections from the primary somatosensory cortex to basal ganglia and thalamus in the monkey. Exp. Brain Res. 30, 481-492.

Kuo, J. S., and Carpenter, M. B. (1973). Organization of pallidothalamic projections in the rhesus monkey. J. Comp. Neurol. 151, 201-236. doi: 10.1002/cne.901510302

Langer, S. Z. (1974). Presynaptic regulation of catecholamine release. Biochem. Pharmacol. 23, 1793-1800. doi: 10.1016/0006-2952(74)90187-7

Laruelle, M. (2000). Imaging synaptic neurotransmission with in vivo binding competition techniques: a critical review. J. Cereb. Blood Flow Metab. 20, 423-451. doi: 10.1097/00004647-200003000-00001

Lee, A. T., Vogt, D., Rubenstein, J. L., and Sohal, V. S. (2014). A class of GABAergic neurons in the prefrontal cortex sends long-range projections to the nucleus accumbens and elicits acute avoidance behavior. J. Neurosci. 34, 11519-11525. doi: 10.1523/JNEUROSCI.1157-14.2014

Matsumoto, M., Kanno, M., Togashi, H., Ueno, K., Otani, H., Mano, Y., et al. (2003). Involvement of GABAA receptors in the regulation of the prefrontal cortex on dopamine release in the rat dorsolateral striatum. Eur. J. Pharmacol. 482, 177-184. doi: 10.1016/j.ejphar.2003.10.003

Nazari-Serenjeh, F., Rezayof, A., and Zarrindast, M. R. (2011). Functional correlation between GABAergic and dopaminergic systems of dorsal hippocampus and ventral tegmental area in passive avoidance learning in rats. Neuroscience 24, 104-114. doi: 10.1016/j.neuroscience.2011.08.073

Nikolaus, S., Beu, M., Antke, C., and Müller, H. W. (2010). Cortical GABA, striatal dopamine and midbrain serotonin as the key players in compulsive and anxiety disorders - Results from in vivo imaging studies. Rev. Neurosci. 21, 119-139. doi: 10.1515/REVNEURO.2010.21.2.119

Nikolaus, S., Beu, M., De Souza Silva, A. M., Huston, J. P., Hautzel, H., Chao, O. Y., et al. (2014a). Relationship between L-DOPA-induced reduction in motor 
and exploratory activity and degree of DAT binding in the rat. Front. Behav. Neurosci. 8:431. doi: 10.3389/fnbeh.2014.00431

Nikolaus, S., Beu, M., De Souza Silva, A. M., Huston, J. P., Hautzel, H., Mattern, C., et al. (2016). Relationship between L-DOPA-induced reduction in motor and exploratory activity and striatal dopamine $\mathrm{D}_{2}$ receptor binding in the rat. Front. Behav. Neurosci. 9:352. doi: 10.3389/fnbeh.2015.00352

Nikolaus, S., Beu, M., de Souza Silva, M. A., Huston, J. P., Antke, C., Müller, $H$. W., et al. (2017). GABAergic control of neostriatal dopamine $D_{2}$ receptor binding and behaviors in the rat. Pharmacol. Biochem. Behav. 153, 76-87. doi: 10.1016/j.pbb.2016.12.012

Nikolaus, S., Beu, M., Hautzel, H., Silva, A. M., Antke, C., Wirrwar, A., et al. (2013). Effects of L-DOPA on striatal iodine-123-FP-CIT binding and behavioral parameters in the rat. Nucl. Med. Commun. 34, 1223-1232. doi: 10.1097/MNM.0b013e3283657404

Nikolaus, S., Hautzel, H., and Müller, H. W. (2014b). Focus on $\mathrm{GABA}_{\mathrm{A}}$ receptor function - a comparative analysis of in vivo imaging studies on neuropsychiatric disorders. Nuklearmedizin 53, 227-237. doi: 10.3413/Nukmed-0647-14-03

Nikolaus, S., Hautzel, H., and Müller, H. W. (2014c). Neurochemical dysfunction in treated and nontreated schizophrenia - a retrospective analysis of in vivo imaging studies. Rev. Neurosci. 25, 25-96. doi: 10.1515/revneuro-2013-0063

Nikolaus, S., Larisch, R., Vosberg, H., Beu, M., Wirrwar, A., Kley, K., et al. (2011). Pharmacological challenge and synaptic response - Assessing dopaminergic function in the rat striatum with small animal SPECT and PET. Rev. Neurosci. 22, 625-645. doi: 10.1515/RNS.2011.054

Paxinos, G., and Watson, C. (2014). The Rat Btain in Stereotaxix Coordinates, 7th Edn. Amsterdam: Academic Press; Elesevier.

Pelleg, D., and Moore, A. (2000). "X-means: extending K-means with efficient estimation of the number of clusters," in Proceedings of the Seventeenth International Conference on Machine Learning (San Francisco, CA: Morgan Kaufmann Publishers Inc.), 727-734.

Powell, E.,W., and Leman, R.B. (1976). Connections of the nucleus accumbens. Brain Res. 105, 389-403. doi: 10.1016/0006-8993(76)90589-8

Precht, W., and Yoshida, M. (1971). Blockage of caudate-evoked inhibition of neurons in the substantia nigra by picrotoxin. Brain Res. 32, 229-233. doi: 10.1016/0006-8993(71)90171-5

Rouse, S. T., Marino, M. J., Bradley, S. R., Awad, H., Wittmann, M., and Conn, P. J. (2000). Distribution and roles of metabotropic glutamate receptors in the basal ganglia motor circuit: implications for treatment of Parkinson's disease and related disorders. Pharmacol.Ther. 88, 427-435. doi: 10.1016/S0163-7258(00)00098-X

Santiago, M., Cano, J., and Westerink, B. H. (1993). Are bilateral nigrostriatal dopaminergic pathways functionally linked in the rat brain? A microdialysis study in conscious rats. Brain Res. 628, 187-192. doi: 10.1016/0006-8993(93)90954-L

Santiago, M., and Westerink, B. H. (1992). The role of GABA receptors in the control of nigrostriatal dopaminergic neurons: dual-probe microdialysis study in awake rats. Eur. J. Pharmacol. 219, 175-181. doi: 10.1016/0014-2999(92)90294-E

Schiffer, W. K., Mirrione, M. M., Biegon, A., Alexoff, D. L., Patel, V., and Dewey, S. L. (2006). Serial microPET measures of the metabolic reaction to a microdialysis probe implant. J. Neurosci. Methods 155, 272-284. doi: 10.1016/j.jneumeth.2006.01.027

Schramm, N., Wirrwar, A., Sonnenberg, F., and Halling, H. (2000). Compact high resolution detector for small animal SPECT. IEEE Trans. Nucl. Sci. 47, 1163-1166. doi: 10.1109/23.856564

Seneca, N., Finnema, S. J., Farde, L., Gulyás, B., Wikström, H. V., Halldin, C., et al. (2006). Effect of amphetamine on dopamine D2 receptor binding in nonhuman primate brain: a comparison of the agonist radioligand [11C]MNPA and antagonist [11C]raclopride. Synapse 59, 260-269. doi: 10.1002/syn.20238
Sesack, S. R., Deutch, A. Y., Roth, R. H., and Bunney, B. S. (1989).Topographical organization of the efferent projections of the medial prefrontal cortex in the rat: an anterograde tract-tracing study with Phaseolus vulgaris leucoagglutinin. J. Comp. Neurol. 290, 213-242. doi: 10.1002/cne.902 900205

Smolders, I., De Klippel, N., Sarre, S., Ebinger, G., and Michotte, Y. (1995). Tonic GABA-ergic modulation of striatal dopamine release studied by in vivo microdialysis in the freely moving rat. Eur. J. Pharmacol. 284, 83-91. doi: 10.1016/0014-2999(95)00369-V

Tomasi, D., and Volkow, N. D. (2013). Striatocortical pathway dysfunction in addiction and obesity: differences and similarities. Crit. Rev. Biochem. Mol. Biol. 48, 1-19. doi: 10.3109/10409238.2012.735642

Ueki, A., Uno, M., Anderson, M., and Yoshida, M. (1977). Monosynaptic inhibition of thalamic neurons produced by stimulation of the substantia nigra. Experientia 33, 1480-1488. doi: 10.1007/BF01918820

Verhoeff, N. P., Bobeldijk, M., Feenstra, M. G., Boer, G. J., Maas, M. A. W., Erdtsieck-Ernste, E., et al. (1991). In vitro and in vivo $\mathrm{D}_{2}$-dopamine receptor binding with $\left(\left({ }^{123} \mathrm{I}\right) \mathrm{IBZM}\right)$ in rat and human brain. Int. J. Rad. Appl. Instrum. B 18, 837-846. doi: 10.1016/0883-2897(91)90091-X

Videbaek, C., Toska, K., Scheideler, M. A., Paulson, O. B., and Moos Knudsen, G. (2000). SPECT tracer [(123)I]IBZM has similar affinity to dopamine D2 and D3 receptors. Synapse 38, 338-342. doi: 10.1002/1098-2396(20001201)38:3\&lt;338::AID-SYN13\&gt;3.0.CO;2-N

Westerink, B. H., Enrico, P., Feimann, J., and De Vries, J. B. (1998). The pharmacology of mesocortical dopamine neurons: a dual-probe microdialysis study in the ventral tegmental area and prefrontal cortex of the rat brain. J. Pharmacol. Exp. Ther. 285, 143-154.

Westerink, B. H., Kwint, H. F., and deVries, J. B. (1996).The pharmacology of mesolimbic dopamine neurons: a dual-probe microdialysis study in the ventral tegmental area and nucleus accumbens of the rat brain. J. Neurosci. 16, 2605-2611.

Westerink, B. H., Santiago, M., and De Vries, J. B. (1992). In vivo evidence for a concordant response of terminal and dendritic dopamine release during intranigral infusion of drugs. Naunyn Schmiedebergs Arch. Pharmacol. 346, 637-643.

Yamamoto, T., Hassler, R., Huber, C., Wagner, A., and Sasaki, K. (1983). Electrophysiologic studies on the pallido- and cerebellothalamic projections in squirrel monkeys (Saimiri sciureus). Exp. Brain Res. 51, 77-87. doi: $10.1007 / \mathrm{BF} 00236805$

Yan, Q. (1999). Focal bicuculline increases extracellular dopamine concentration in the nucleus accumbens of freely moving rats as measured by in vivo microdialysis. Eur. J. Pharmacol. 385, 7-13. doi: 10.1016/S0014-2999(99)00699-8

Yoshida, M., Yokoo, H., Nakahara, K., Tomita, M., Hamada, N., Ishikawa, M., et al. (1997). Local muscimol disinhibits mesolimbic dopaminergic activity as examined by brain microdialysis and Fos immunohistochemistry. Brain Res. 767, 356-360. doi: 10.1016/S0006-8993(97) 00474-5

Conflict of Interest Statement: The authors declare that the research was conducted in the absence of any commercial or financial relationships that could be construed as a potential conflict of interest.

Copyright (c) 2018 Nikolaus, Wittsack, Beu, Antke, De Souza Silva, Wickrath, MüllerLutz, Huston, Antoch, Müller and Hautzel. This is an open-access article distributed under the terms of the Creative Commons Attribution License (CC BY). The use, distribution or reproduction in other forums is permitted, provided the original author(s) and the copyright owner are credited and that the original publication in this journal is cited, in accordance with accepted academic practice. No use, distribution or reproduction is permitted which does not comply with these terms. 